Texas Children's Center for Vaccine

Development, Department of Pediatrics and Molecular Virology and Microbiology, National School of Tropical Medicine,

Baylor College of Medicine, Houston, TX, USA

hotez@bcm.edu

Cite this as: $B M J$ 2021;373:n657 http://dx.doi.org/10.1136/bmj.n657 Published: 09 April 2021

\title{
ESSAY
}

\section{Covid-19: a disaster five years in the making}

\section{The covid-19 pandemic is not a one-off extraordinary event but the culmination of a five year unravelling of progress in global health, writes Peter Hotez}

\section{Peter Hotez professor of paediatrics and molecular virology and microbiology}

We live in extraordinary times in global health. Through two decades of the United Nations' millennium and sustainable development goals, the number of childhood deaths from measles and some other vaccine preventable infections has fallen by as much as $87 \% .^{1}$ The launch and support of global vaccination programmes through Gavi, the Vaccine Alliance, and mass treatment programmes for HIV-AIDS, malaria, tuberculosis, and neglected tropical diseases have produced enormous global health gains. ${ }^{1}$ We are also moving towards the elimination of neglected tropical diseases including onchocerciasis, lymphatic filariasis, scabies, yaws, and trachoma, with major falls in the incidence of AIDS in Africa and elsewhere.

The benefits of these successes go beyond public health to reduced poverty through improvements in productivity, child development, and maternal-fetal outcomes. Global security has also been strengthened. Over the past 5-6 years, however, we have seen abrupt reversals in these developments leading to the emergence or re-emergence of both vaccine preventable diseases and neglected infections in multiple areas of the world. And that's before the onset of covid-19.

Humanity is able to make tremendous gains against global disease like never before-but we have allowed those gains to unravel. The novel coronavirus has shown us the consequences of this.

\section{Political instability and social collapse}

Between 2015 and 2020 a group of new social determinants, sometimes working synergistically with climate change, accelerated to halt or collapse health systems and bring back illness globally. ${ }^{1}$

Among the most potent of these were political instability and conflict. In Venezuela, failed policies of the Maduro regime together with dropping oil prices in 2015 precipitated a total socioeconomic collapse that began under former president Hugo Chavez. Interruption to childhood vaccination programmes contributed to measles epidemics in 2017 and 2018 that extended across international borders into Colombia and the Amazon region of Brazil. $^{2}$

Human migrations, emigration, and internal displacements also contributed to the rise in disease. Indigenous groups, such as the Yanomami tribe of Brazil, suffered massive losses. Lack of employment also forced many Venezuelans to work in illegal gold mining, where they slept in mosquito infested areas without bed nets, resulting in widespread malaria.

Elsewhere in Latin America, illegal drug trafficking shifted or extended from Colombia to the northern triangle of El Salvador, Guatemala, and Honduras. This led to violence and economic declines that might have helped to slow vector control and promote vectorborne illnesses, including Chagas disease, dengue, zika virus infection, and leishmaniasis. ${ }^{3}$

On the Arabian peninsula, the Syrian civil war and Islamic State occupation similarly caused a return of measles, polio, and other infections that are preventable by vaccine, as well as the re-emergence of cutaneous leishmaniasis. ${ }^{4}$ Human displacements spread this illness across the Middle East-in some cases infected people living in refugee camps were then bitten by local sandflies to create new epidemic foci. Leishmaniasis also rose in Yemen from health system breakdowns caused by a proxy war between Iran and Saudi Arabia, as did cholera, resulting in one of the world's largest epidemics, which peaked in $2017 .^{5}$

In the conflict zones of South Sudan, Democratic Republic of the Congo, and Central African Republic, measles also returned, as did epidemics of visceral leishmaniasis and sleeping sickness. The areas of northern Nigeria occupied by Boko Haram have experienced similar disease re-emergence problems. ${ }^{6}$

\section{Heating up}

Climate change is a key driver of disease spread, working mostly in concert with other forces. ${ }^{1}$ Warming and drought have perpetuated existing political instabilities. In 2015, unprecedented temperatures that exceeded $50^{\circ} \mathrm{C}, 7$ combined with drought, caused the abandonment of ancient agricultural lands in the Middle East, as did a prolonged drought in Venezuela, with 50-65\% declines in rainfall between 2013 and 2016. ${ }^{1}$ Warming temperatures have also fuelled the rise of vectorborne diseases such as arbovirus infections, leishmaniasis, and Chagas disease in southern Europe and the United States (Texas and the Gulf Coast). Snailborne schistosome infections have emerged on the French island of Corsica. ${ }^{8}$

Occurring alongside political instability, human displacements, and climate change is rapid urbanisation, which includes the formation of megacities of 10 million people or more. Caracas in Venezuela, Kinshasa in DR Congo, Lagos in Nigeria, and Aleppo in Syria are now foci of disease and 
poverty, with urban transmission of vectorborne infections, enteric infections such as cholera, and parasitic helminth infections, including hookworm and schistosomiasis. ${ }^{9}$ In some cases, urbanisation combined with deforestation has created new opportunities for catastrophic viral infections transmitted from bats, including Ebola and Nipah virus infections. ${ }^{10} 11$

\section{Shifting poverty}

The number of people who live in extreme poverty, defined as $\$ 1.90$ (£1.40; €1.6o) a day by the World Bank, has diminished by more than one billion since the launch of the millennium and sustainable development goals. ${ }^{12}$ But more than 700 million people still live in extreme poverty, ${ }^{13}$ with almost all of these people affected by at least one neglected disease.

Over the 20 year period since the global goals were launched, there have been some important geographic shifts in both poverty and disease. One is the finding that people who live in extreme poverty amid wealth in the G20 nations might account for most of the world's neglected diseases, including tuberculosis, dengue, worm infections, leishmaniasis, Chagas disease, leprosy, among others. ${ }^{14}$ This is a new normal, pivoting away from the traditional norms of global health (poor versus wealthy nations, or the global north versus the global south) to one of poverty amid prosperity. ${ }^{14}$ Such findings have important policy implications stemming from the fact that support for mass treatments or vaccinations against poverty related illness is no longer primarily a resource issue.

Given that the G2o nations account for almost $90 \%$ of the global economy, our inability to treat and prevent disease shows failures in leadership and adequately targeted advocacy. Most of the world's nuclear powers, including India, North Korea, Pakistan, and Russia, probably devote more resources to the research and stockpiling of sophisticated weapons than to research and development for vaccines and neglected diseases. ${ }^{14}$

Thus, war, political collapse, internal displacements, climate change, urbanisation, and shifting poverty combine in unique and interesting ways to promote widespread emergence of infectious and tropical diseases (fig 1).

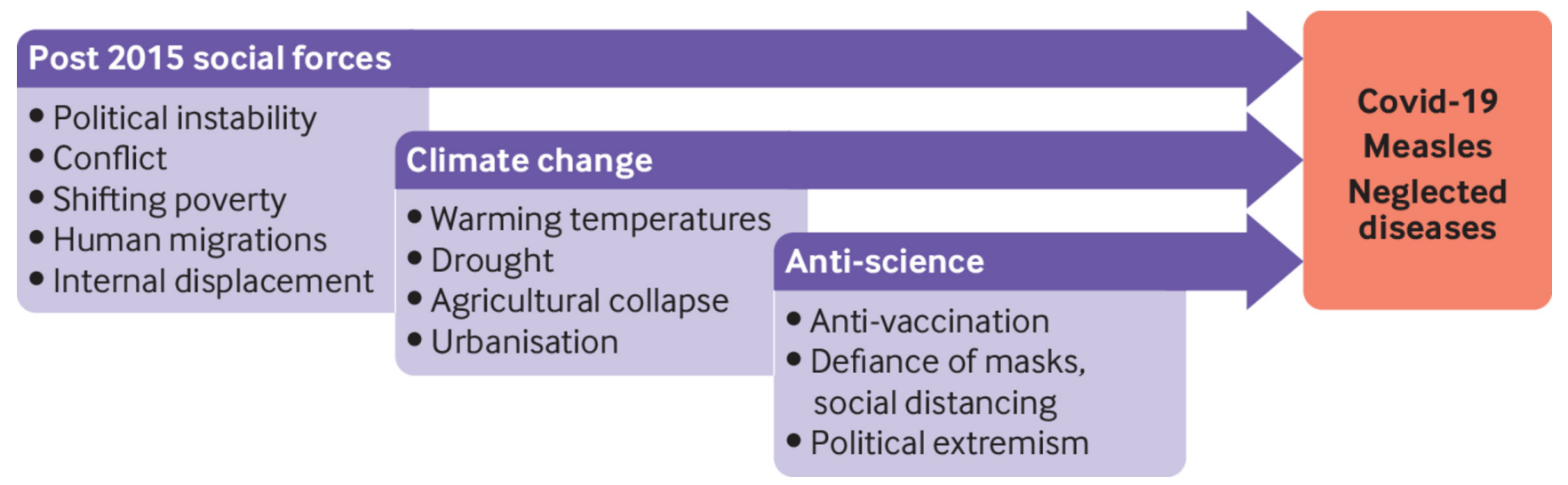

Fig $1 \mid A$ build-up of 21st century forces resulting in illness

\section{Anti-science sentiment}

Occurring alongside these forces was the globalisation of an anti-science movement that accelerated in the US after 2015. ${ }^{15}$ That year saw the start of Donald Trump's presidential campaign, together with anti-vaccine protests in southern California. These followed efforts by the California legislature to halt the practice of vaccine exemptions (for non-medical reasons) after a large measles outbreak was linked to Disneyland. A rising health freedom movement then expanded into Texas and other western and midwestern states leading to the formation of anti-vaccine political action committees branded as "vaccine choice" or "vaccine freedom," in some cases attached to the conservative "tea party" movement that had formed a few years earlier. The consequence of this was a sharp rise in vaccine exemptions leading to 22 measles outbreaks mostly affecting unvaccinated people. ${ }^{16}$

As measles expanded across the US, outbreaks occurred in Samoa and American Samoa in the South Pacific that might have been influenced by antivaccine groups. ${ }^{17}$ In parallel, lapses in vaccine confidence were coalescing across Europe resulting in the return of measles, with almost 100 ooo measles cases each in 2018 and 2019. Vaccine declines extended east into Ukraine and other former Eastern bloc nations. In 2019, the World Health Organization listed vaccine hesitancy as one of its top 10 global health threats. ${ }^{18}$
There is now also strong evidence (from US and British intelligence) that the Russian president, Vladimir Putin, launched programmes of "weaponised health communication" that fill the internet with covid-19 conspiracies and anti-vaccine messages. ${ }^{1519}$ Russia is now a leading source of anti-science disinformation.

\section{A vulnerable planet versus covid-19}

These factors established the conditions for covid-19 to spread rapidly across the continents. Although climate change and outright conflict have had no obvious role in promoting covid-19 so far, other determinants are clear drivers, and there is an association between factors linked to the ascendancy of the novel coronavirus with those that destabilise global health more generally and the return of vaccine preventable or neglected diseases.

A ranking of countries with the most covid-19 cases and deaths has G2O nations such as the US, Brazil, South Africa, and the United Kingdom at the top. ${ }^{14}$ Moreover, low income neighbourhoods are disproportionately associated with hospital admissions and deaths from covid-19. ${ }^{14}$ In the US, African American and Hispanic groups who live in poor neighbourhoods experience substantially higher rates of covid-19 hospital admissions and deaths. Poverty in prosperous nations is a clear driving force for the spread of covid-19.

Global urbanisation also plays a key role, as most cases reported to date occurred in large cities and crowded urban slums. This 
situation is about to get worse given new findings that more than 100 million additional people have been thrown back into extreme poverty as a result of economic collapse from the pandemic and measures to control it. ${ }^{20}$

Political instability from populism and political extremism is another factor in the rise of covid-19 in countries such as the US, Brazil, Mexico, Nicaragua, and the Philippines, where autocratic heads of state have exaggerated their efforts to control the pandemic while downplaying the severity of it. ${ }^{21}$ Populist leaders have also promoted "spectacular" cures with uncertain or little medicinal benefits such as hydroxychloroquine. ${ }^{21}$

Ultimately, the high death toll from covid-19 has not arisen from SARS-CoV-2 transmission alone, but also anti-science forces promoting defiance against vaccines, face masks, and social distancing. In the summer of 2020, far right political extremism, in some cases linked to fringe movements such as QAnon, perpetuated the anti-mask and anti-vaccine rallies in western European capitals. ${ }^{15}$ Far right political allegiance to health freedom in the US espoused shunning covid-19 prevention measures in conservative leaning southern and midwest states, where it contributed to massive losses in human life.

\section{Repair}

Developing next generation vaccines and other biotechnologies is essential for suppressing covid-19, but our way out of this pandemic cannot rely entirely on technology. This is also true for other vaccine preventable illnesses and neglected diseases. We must protect our cities better from urban environmental degradation leading to enteric and vectorborne diseases. We must demand greater cooperation between the wealthy G20 nations to fight poverty and poverty related illness within their own borders while working together to support new biotechnologies.

Too often in 2020, the major G20 countries (including China, Russia, the UK, and the US) opted for a go-it-alone vaccine access strategy or negotiated bilateral vaccine sales to low and middle income countries. ${ }^{21}$ This vaccine nationalism now leaves many countries without access to covid-19 vaccines. We must reset and reframe international cooperation around science to promote vaccine diplomacy, ${ }^{1}$ especially for the next generation covid-19 vaccines required for new variants.

In parallel, we must find a path to tackle the dramatic rise in anti-science rhetoric, creating a system of G20 cooperation to resist the influence of far right wing extremist groups like QAnon, while working to halt Russia's systematic programme of weaponised health communication. ${ }^{15} 19$

Five years of unravelling is enough. Tackling pandemics and other infectious disease threats will require our community of biomedical scientists and public health professionals to go out of our comfort zone and confront some hard geopolitical realities and imminent threats. We must steel ourselves to avoid another covid-19, or worse.

\footnotetext{
Biography

Peter Hotez is a vaccine scientist and professor of paediatrics and molecular virology and microbiology at Baylor College of Medicine, where he is also the founding dean of the National School of Tropical Medicine and Texas Children's Hospital endowed chair in tropical paediatrics. $\mathrm{He}$ is the author of 580 publications and four books, including Preventing the Next Pandemic: Vaccine Diplomacy in a time of Anti-Science Johns Hopkins University Press), related to the subject of this article. He is an elected member of the National Academy of Medicine and the American Academy of Arts and Sciences.
}

Provenance and peer review: Commissioned; not externally peer reviewed.

Competing interests: $\mathrm{PH}$ is an inventor on a covid-19 vaccine technology owned by Baylor College of Medicine (BCM) that was recently licensed non-exclusively to a company. In discussing with our compliance office, since the technology is owned and licensed by BCM, it would not be considered a significant financial interest per Public Health Service regulations. He is also an inventor on non-revenue generating patents for parasitic disease vaccines and an author of four books (published by Johns Hopkins University Press and American Society of Microbiology ASM Press) related to the geopolitics of emerging and neglected diseases.

Hotez PJ. Preventing the next pandemic: vaccine diplomacy in a time of anti-science. Johns Hopkins University Press, 2021.

2 Paniz-Mondolfi AE, Tami A, Grillet ME, etal. Resurgence of vaccine-preventable diseases in Venezuela as a regional public health threat in the Americas. Emerg Infect Dis 2019;25:625-32. doi: 10.3201/eid2504.181305 pmid: 30698523

3 Hotez PJ, Damania A, Bottazzi ME. Central Latin America: Two decades of challenges in neglected tropical disease control. PLoS Negl Trop Dis 2020;14:e0007962.

4 Ozaras R, Leblebicioglu H, Sunbul M, etal. The Syrian conflict and infectious diseases. Expert Rev Anti Infect Ther 2016;14:547-55. doi: 10.1080/14787210.2016.1177457 pmid: 27063349 Blackburn CC, Lenze PE, JrCasey RP. Conflict and cholera: Yemen's man-made public health crisis and the global implications of weaponizing health. Health Secur 2020;18:125-31. doi: 10.1089/hs.2019.0113 pmid: 32324073

6 Sato R. Effect of armed conflict on vaccination: evidence from the Boko haram insurgency in northeastern Nigeria. Confl Health2019;13:49. doi: 10.1186/s13031-019-0235-8 pmid: 31673285

7 Shaheen K, Kamali Dehghan S. Middle East swelters in heatwave as temperatures top 50C. Guardian 4 Aug 2015. https:/www.theguardian.com/world/2015/aug/04/middle-east-sweltersin-heatwave-as-temperatures-top-50c

8 Rothe C, Zimmer T, Schunk M, etal. Developing endemicity of schistosomiasis, Corsica, France. Emerg Infect Dis 2021;27:319-21. doi: 10.3201/eid2701.204391 pmid: 33264582

9 Hotez PJ. Global urbanization and the neglected tropical diseases. PLoS Negl Trop Dis 2017;11:e0005308. doi: 10.1371/journal.pntd.0005308 pmid: 28231246

10 Moyen N, Thirion L, Emmerich P, etal. Risk factors associated with Ebola and Marburg viruses seroprevalence in blood donors in the Republic of Congo. PLoS Neg/ Trop Dis 2015;9:e0003833. doi: 10.1371/journal.pntd.0003833 pmid: 26047124

11 Chattu VK, Kumar R, Kumary S, Kajal F, David JK. Nipah virus epidemic in southern India and emphasizing "one health" approach to ensure global health security. J Family Med Prim Care 2018;7:275-83. doi: 10.4103/jfmpc.jfmpc_137_18 pmid: 30090764

12 Roser M, Ortiz-Ospina E. Global extreme poverty. Our World in Data. https://ourworldindata.org/extreme-poverty

13 World Bank. Poverty. https://www.worldbank.org/en/topic/poverty/overview

14 Hotez PJ. Poverty and the impact of covid-19: the blue-marble health approach. Project Muse. Johns Hopkins University Press, 2020. https://muse.jhu.edu/book/75688

15 Hotez PJ. Anti-science kills: from Soviet embrace of pseudoscience to accelerated attacks on US biomedicine. PLoS Biol2021;19:e3001068. doi: 10.1371/journal.pbio.3001068 pmid: 33507935

16 Patel M, Lee AD, Clemmons NS, etal. National Update on Measles Cases and Outbreaks-United States, January 1-October 1, 2019. MMWR Morb Mortal Wkly Rep 2019;68:893-6. doi: 10.15585/mmwr.mm6840e2 pmid: 31600181

17 Guarino B, Satija N, Sun LH. Deadly measles outbreak hits children in Samoa after anti-vaccine fears. Washington Post2019 Nov 27. https://www.washingtonpost.com/health/2019/11/26/deadlymeasles-outbreak-hits-children-samoa-after-anti-vaccine-fears/

18 World Health Organization. Ten threats to global health in 2019. https://www.who.int/newsroom/spotlight/ten-threats-to-global-health-in-2019

19 Broniatowski DA, Jamison AM, Qi S, etal. Weaponized health communication: twitter bots and Russian trolls amplify the vaccine debate. Am J Public Health 2018;108:1378-84. doi: 10.2105/AJPH.2018.304567 pmid: 30138075

20 Hotez PJ, Fenwick A, Molyneux D. The new COVID-19 poor and the neglected tropical diseases resurgence. Infect Dis Poverty2021;10:10. doi: 10.1186/s40249-020-00784-2. pmid: 33509283

21 Lancet Commission on COVID-19 Vaccines and Therapeutics Task Force Members. Urgent needs of low-income and middle-income countries for COVID-19 vaccines and therapeutics. Lancet 2021;397:562-4. doi: 10.1016/S0140-6736(21)00242-7 pmid: 33516284

This article is made freely available for use in accordance with BMJ's website terms and conditions for the duration of the covid-19 pandemic or until otherwise determined by BMJ. You may use, download and print the article for any lawful, non-commercial purpose (including text and data mining) provided that all copyright notices and trade marks are retained. 